\title{
Biological properties of brittle star Ophiocnemis marmorata collected from Parangipettai, Southeast coast of India
}

\author{
K. Prabhu and S. Bragadeeswaran* \\ Centre of Advanced Study in Marine Biology, Faculty of Marine Sciences, Annamalai University, \\ Parangipettai - 608 502, India.
}

Accepted 5 September, 2013

\begin{abstract}
The classes Ophiuroidea (Brittle stars) and Asteroids (sea stars) belonging to phylum, Echinodermata are characterized by their toxic saponins content. The aim of the present observation was to study the antimicrobial, hemolytic and cytotoxic properties of crude extracts from Ophiocnemis marmorata. The antimicrobial activity of ethanol extract showed maximum zone of inhibition against Staphylococcus aureus $(7.0 \mathrm{~mm})$ followed by $5.0 \mathrm{~mm}$ inhibition against Escherichia coli and $4 \mathrm{~mm}$ against Vibrio parahaemolyticus and Salmonella typhi. Hemolytic activity was high in goat blood (128 HU) in methanolic extracts. Thin layer chromatography indicates the presence of steroidal compounds in the crude sample. The brine shrimp lethality assay showed maximum mortality at $100 \%$ for of 93.6 and $95 \%$ ethanol extracts and minimum amount of mortality was noticed at $20 \%$ concentration. The regression analysis showed $\mathrm{LC}_{50}$ value of $55.3 \%$ in ethanol and $56.3 \%$ in methanol extract. Therefore, it is concluded in the present investigation that the steroidal related compounds present in crude extract were responsible for the cytotoxicity activity.
\end{abstract}

Key words: Asteroids, antimicrobial, hemolytic, cytotoxic, steroids.

\section{INTRODUCTION}

The phylum, Echinodermata, which comprises about 6000 living species, is divided into five classes: Crinoidea (sea lilies and feather stars), Holoturoidea (sea cucumbers or holothurians), Echinoidea (sea urchins), Asteroidea (sea stars or starfishes) and Ophiuroidea (brittle stars). The echinoderms, starfishes and sea cucumbers usually contain saponins, which are responsible for their general toxicity. Chemically, saponins derived from sea cucumbers are triterpenoid glycosides whereas those from starfishes are steroidal glycosides. The presence of oligoglycosides in both Holothuroidea and Asteroidea class gives support to the opinion that sea cucumbers and starfishes are phylogenetically closely related (Luigi et al., 1995). Seeman et al. (1973) stated that hemolysis is caused by the abstraction of membrane cholesterol by the saponins.

Brittlestars have long arms and a relatively small, welldefined central disc. Ophiuroidea is the largest living echinoderm class, comprising about 1800 species, with representatives in all benthic environments from the intertidal zone to the deep ocean; and found in all seas. The huge potential of echinoderms fairly untapped source of bioactive molecules includes the usefulness of echinoderm derived molecules for therapeutic application in selected fields of cancer research, in the control of bacterial growth as substances with new antibiotic 


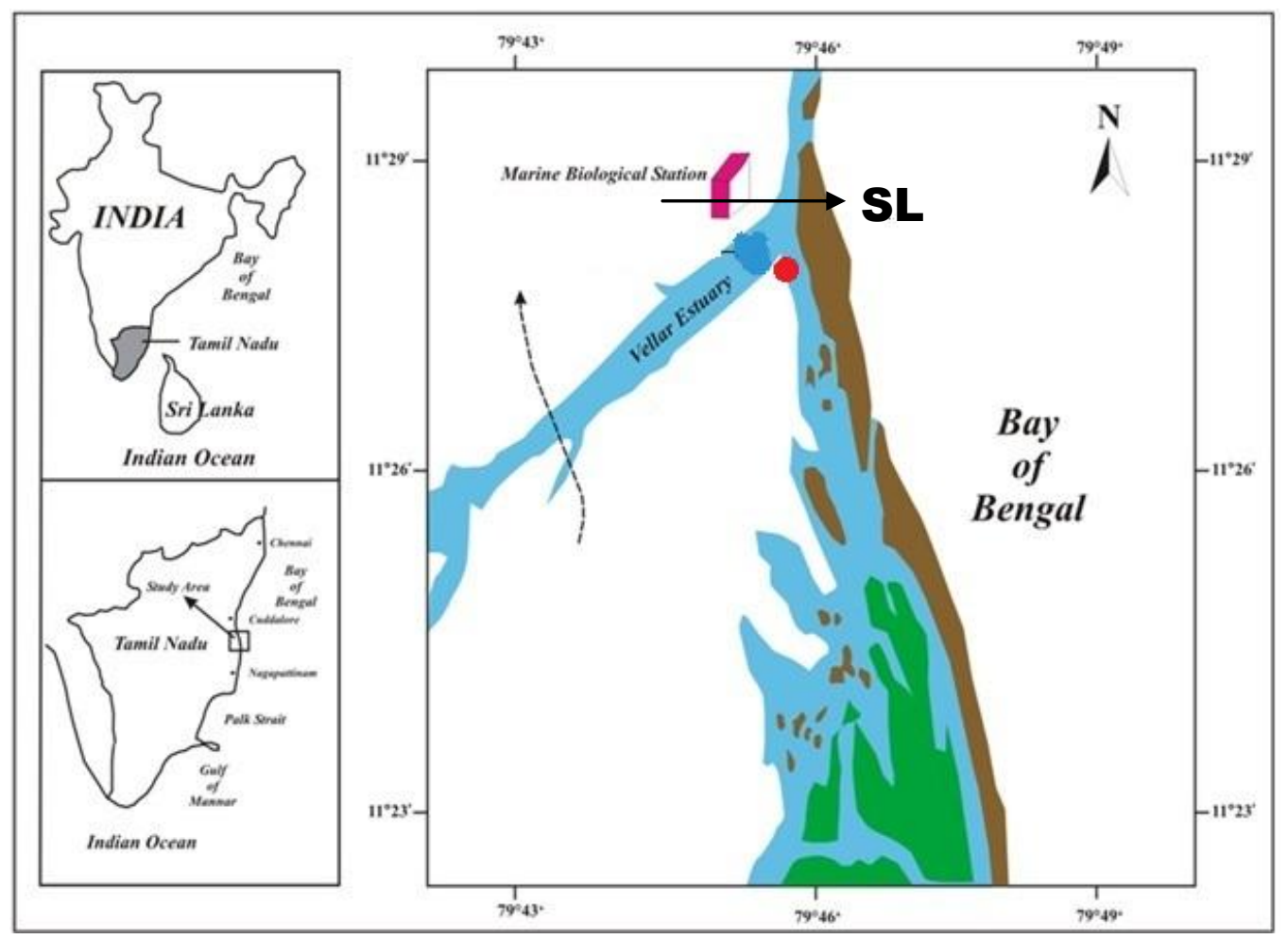

Figure 1. Sample location (Mudasal odai fish landing centre).

properties, and finally in the context of technical applications such as antifouling substances.

In the present investigation has revealed that bioactive compounds from brittle star Ophiocnenmis mormorata and applied for biological properties.

\section{MATERIALS AND METHODS}

\section{Collection and identification}

The brittle star $O$. marmorata was collected from Mudasalodai fish landing centre (SL) (Figure 1), Southeast coast of Tamilnadu and brought to the laboratory; it was kept in seawater in fresh condition and immediately air dried for further analysis. The specimen was identified by using manual of taxonomy of echinodermata (James, 2008).

\section{Extraction}

The extraction was done following the method of Braekman et al. (1992) with certain modifications. Different solvent extraction was done by using ethanol, methanol and kept standing for one week. The solvent was filtered through Whatman No.1 filter paper (pore size $0.4 \mu \mathrm{m}$ ). The solvent was removed at low pressure using rotary evaporator Lark LICB-7.5L at $30^{\circ} \mathrm{C}$. The resultant compound was finally dried in vacuum desiccators and stored at $4^{\circ} \mathrm{C}$ in a refrigerator for future use.

\section{Analytical thin layer chromatography}

The crude extract and fractions were subjected to TLC and grouped into fractions. Samples were analysed by TLC coupled to chemical tests for identification of different secondary metabolites according to MINSAP (1995). For analytical TLC, aluminium sheets $(4 \times 5 \mathrm{~cm})$ coated with silica gel 60 F254 were used. The chromatography was run in a chamber with chloroform: methanol as medium (9:1) at the mobile phase under UV light at $254 \mathrm{~nm}$. This crude extract was further studied for biological activities.

\section{Antimicrobial activity}

\section{Antibacterial assay}

Antibacterial screening was performed by disc diffusion according to Bauer et al. (1966) using Whatman No. 1 filter paper discs (4 $\mathrm{mm}$ diameter) which were impregnated with known amount of test samples of the tissue extracts; tetracycline was used as a positive control disc. Bacterial assay was done by petriplating method in commercially formulated nutrient agar medium (Hi-media) which consists of beef extract $(0.3 \%)$, peptone $(0.5 \%)$ and agar $(1.5 \%)$. All the ten bacterial strains were inoculated in a nutrient broth medium individually for $24 \mathrm{rs}$ at $27^{\circ} \mathrm{C}$ in bacteriological incubator. After $24 \mathrm{~h}$ inoculation, each bacterial strain was streaked in agar plate by sterile cotton swab.

A range of ten different bacterial strains was used which consisted of one gram positive bacteria (Staphylococcus aureus) and nine gram negative bacterium (Salmonella typhi, Salmonella paratyphi, Klebsilla oxytoca, Vibrio parahemolyticus, Vibrio cholerae, Eschericia coli, Proteus mirabilis and Klebsilla pneumoniae). The impregnated discs along with the control were kept at the center of agar plates, seeded with test bacterial cultures. After incubation at room temperature $\left(27^{\circ} \mathrm{C}\right)$ for 24 hantibacterial activities were expressed in terms of diameter of zone of inhibition which was measured in $\mathrm{mm}$ using caliper or a scale and recorded. 


\section{Antifungal assay}

Antifungal activity was determined against fungi following the method of Bauer et al. (1966). The stock culture was maintained in glucose, peptone, yeast and sucrose (GPYS) medium. Fungal inoculums $(0.2 \mathrm{~mL})$ of $48 \mathrm{~h}$ old culture were distributed uniformly on the surface of agar plates containing GPYS medium with the help of a sterile cotton swab. Culture medium was prepared by adding dextrose $\left(20 \mathrm{~g} \mathrm{~L}^{-1}\right)$, peptone $\left(10 \mathrm{~g} \mathrm{~L}^{-1}\right)$ and agar $\left(25 \mathrm{~g} \mathrm{~L}^{-1}\right)$ in distilled water and was sterilised in an autoclave at a pressure of $15 \mathrm{lbs}$ and a temperature of $120^{\circ} \mathrm{C}$. At the time of inoculation, the disc impregnated with crude extract $\left(100 \mathrm{\mu g} \mathrm{g}^{-1}\right.$ of disc of $10 \mathrm{~mm}$ diameter) was placed. The inhibition zone was measured after incubation period of $48 \mathrm{~h}$.

\section{Hemolytic study}

\section{Hemolytic assay}

The crude extract of Protoreaster linckii was assayed on chicken, sheep and human erythrocytes following the method of Pani Prasad and Venkateshvaran (1997). The chicken and sheep blood was obtained from nearby slaughterhouse in Parangipettai, while clinically healthy human blood was obtained from a local hospital using $2.7 \%$ ethylene diamine tetra acetic acid (EDTA) solution as an anticoagulant at $5 \%$ of the blood volume. This was brought to the laboratory. The blood was centrifuged thrice at 5,000 rpm for 5 $\min .1 \%$ erythrocyte suspension was prepared for hemolytic study.

The hemolytic test was performed in 96-well ' $v$ ' bottom microtitre plates. Serial two-fold dilutions of the crude sample $(0.1 \mathrm{mg} / 1 \mathrm{ml}$ saline) were made in $100 \mu \mathrm{L}$ of normal saline. Then, $100 \mu \mathrm{L}$ of $1 \%$ erythrocyte was added to all the wells. For positive control, $100 \mu \mathrm{L}$ of distilled water and for negative control $100 \mu \mathrm{L}$ of normal saline were added respectively to the $1 \%$ red blood cell (RBC) suspension. The plate was gently shaken and allowed to stand for 2 $\mathrm{h}$ at room temperature. Presentation of uniform red color suspension in the wells was considered to be positive hemolysis and a formation of button in the bottom of the wells constituted a lack of hemolysis. The reciprocal of the highest dilution of the sample showing the hemolytic pattern (hemolytic unit) was divided by the protein content to obtain the specific hemolytic titer. Haemolytic assay was also performed in methanol fraction and aqueous fraction.

\section{Hemolytic assay on blood agar plates}

The hemolytic activity was assayed using blood agar plates by following the method of Marques and Yano (2004). Chicken agar plates were prepared by adding $5 \mathrm{ml}$ of blood to $95 \mathrm{ml}$ of sterile blood agar aseptically, with the result poured immediately onto the Petri dishes. After solidification, the wells were cut into the agar plate-using a corkscrew borer (8 $\mathrm{mm}$ diameter). Wells were loaded with $50 \mu \mathrm{L}(1 \mathrm{mg} / \mathrm{ml})$ of samples. The plates were observed for hemolysis after overnight incubation at room temperature.

\section{Cytotoxicity using brine Shrimp Lethality Assay}

To determine the toxicity effects on $A$. salina (brine shrimp) the method of Meyer et al. (1982) was followed. The extracts were dissolved in $0.01 \mathrm{ml}$ of DMSO and incorporated into $5 \mathrm{ml}$ of sea water $(\mathrm{pH}=8.8$ and salinity $=28 \% \mathrm{o})$ containing ten $A$. salina. Each concentration $(10,20,40,60,80$ and $100 \mu \mathrm{g} / \mathrm{mL}$ ) was tested thrice, and a control DMSO was done each time. The vials were maintained under illumination. Survivals were counted after $24 \mathrm{~h}$ and the percentage of deaths at each dose and control (DMSO and saline water). The $\mathrm{LC}_{50}$ values of brine shrimp were obtained from counts using the prohibit analysis method described by Litchfield and Wilcoxon (1941).

\section{Fourier transform Infrared Spectroscopy (FT-IR)}

Chemical characterisation of samples was performed using Fourier transformed infrared (FTIR) spectroscopy. For this purpose starfish extracts were reduced to powder and analysed as potassium bromide $(\mathrm{KBr})$ pellets using a Shimdzu FTIR Modal spectrometer (Abu et al., 1991).

\section{RESULTS}

\section{Antibacterial activity}

The zones of inhibition in different bacterial strains against different solvent extract of starfish $O$. marmorata were illustrated (Figures 2 and 3). In the case of ethanol extract, the maximum zone of inhibition was recorded against $S$. aureus $(7.0 \mathrm{~mm})$ followed by $5.0 \mathrm{~mm}$ inhibition against $E$. coli and $4 \mathrm{~mm}$ against Vibrio parahaemolyticus and $S$. typhi. The positive control showed $15 \mathrm{~mm}$ against K. pneumonia, $14 \mathrm{~mm}$ against $S$. aureus followed by 12 $\mathrm{mm}$ against $V$. cholera and $V$. parahemolyticus. One way analysis of variance (ANOVA) showed significance at $0.05 \%$ level $(p>0.05)$ between the extracts used.

The methanol extracts exhibited the maximum zone of inhibition against $K$. oxytoca $(9 \mathrm{~mm})$ followed by $K$. pneumonia and $E$. coli $(7 \mathrm{~mm})$. One way ANOVA showed significance at $0.05 \%$ level $(p>0.05)$ between the extracts and positive control used.

\section{Antifungal activity}

Antifungal activities were represented (Figure 4) by the zone of inhibition around the disc. It showed moderate antifungal activity against all fungal pathogens assayed. Rhizopus sp., was most sensitive against methanol and ethanol extracts.

\section{Hemolytic activity}

\section{Haemolytic assay in microtitre plate}

Crude extract of $O$. marmorata was assayed using chicken and goat blood (RBCs) (Figure 5). The hemolytic activity was high in goat blood (128 HU) in methanolic extracts whereas the ethanolic extracts showed moderate lysis against chicken blood erythrocytes.

Hemolytic activity was further confirmed using blood agar plates with chicken blood. The zone of inhibition was measured after incubation. Crude methanol and ethanol extracts showed $2.6 \mathrm{~mm}$ inhibition in ethanol extract whereas $4.3 \mathrm{~mm}$ inhibition in methanol extract (Figure 5).

Thin layer chromatography on silica gel coated plates with butanol: Ethyl acetate: water (4:1:2), Ethanol: Ethyl 


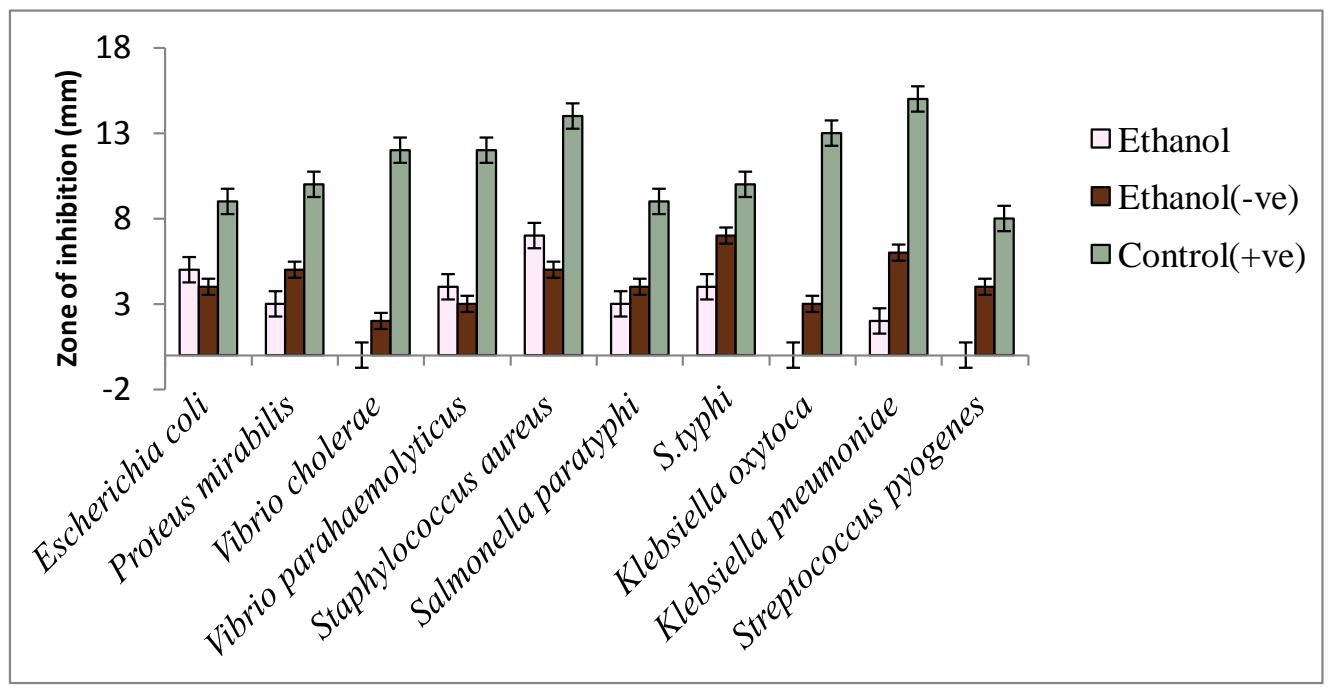

Figure 2. Antibacterial activity of ethanol extract from O. marmorata against pathogens.

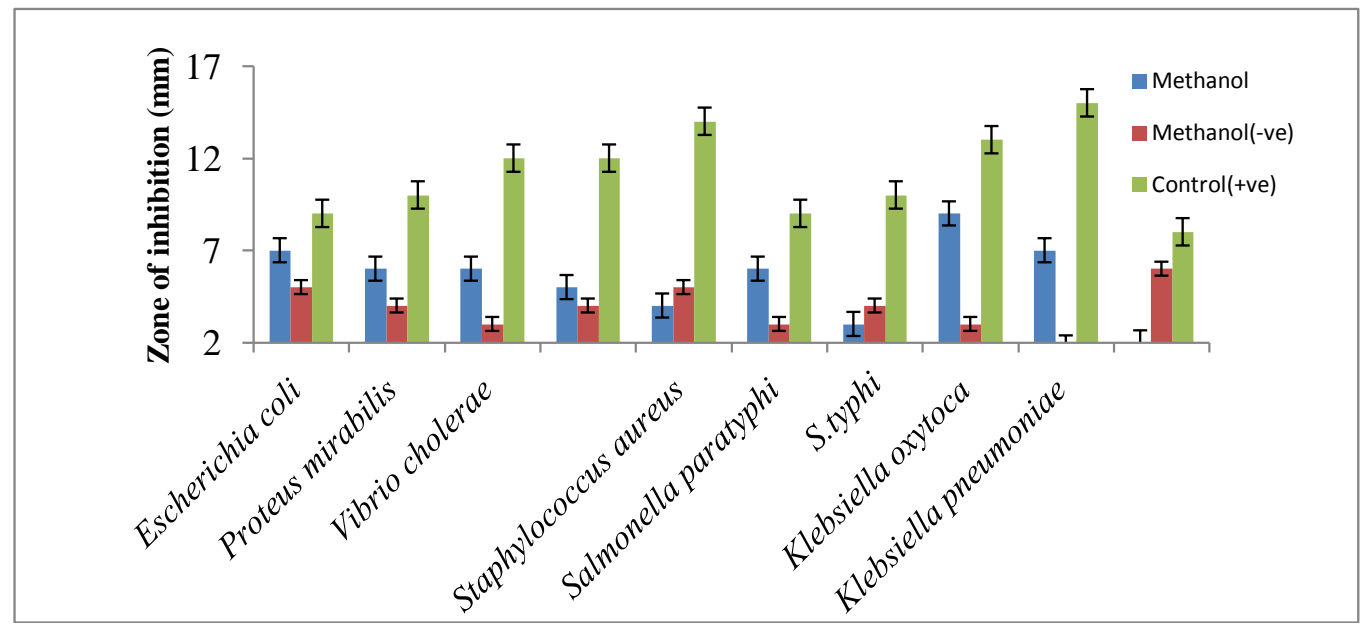

Figure 3. Antibacterial activity of methanol extract from $O$. marmorata against pathogens.

acetate: Hexane (7:2:1) and Isopropyl alcohol: Ethanol:

$\mathrm{NH}_{4} \mathrm{OH} \quad(6: 3.5: 0.5)$ showed an intensive spot after spraying $1 \%$ ninhydrin solution in methanol. Figure $6 \mathrm{~A}$ and $\mathrm{B}$ does not exhibit the separate band.

Isopropyl alcohol: ethanol: $\mathrm{NH}_{4} \mathrm{OH}(6: 3.5: 0.5)$ solvent system showed the distinct band (Figure $6 \mathrm{c}$ ). $R_{\mathrm{f}}=6,4$, 4.5 for ethanol extract and 6.3, 5.6, and 3.6 of water extract under UV light at $254 \mathrm{~nm}$. After spraying with ninhydrin, it showed pale brown colour bands, which indicate the presence of steroidal compounds present in the sample.

\section{Brine shrimp lethality test}

In the brine shrimp lethality assay, the degree of inhibition observed was directly related to the concentration of the active 0 . marmorata extract. The concentration level was $20 \%$ to $100 \%$ (Figure 7 ). The maximum mortality was noticed at $100 \%$ concentration of 93.6 and $95 \%$ ethanol extracts and minimum amount of mortality was noticed at $20 \%$ concentration. The regression analysis showed $\mathrm{LC}_{50}$ value of $55.3 \%$ in ethanol and $56.3 \%$ in methanol extract.

\section{Fourier Transform infrared spectroscopy}

The FTIR spectrum of methanolic extract of brittle star $O$. marmorata exhibited many peaks (Figures 8 and 9) and absorption at 406.98 to $3967.57 \mathrm{~cm}^{-1}$. The $\mathrm{N}-\mathrm{H}$ stretches (Primary amine groups) and $\mathrm{C}-\mathrm{H}$ stretches (alkyl group)1216.51-1047.42 $\mathrm{cm}^{-1}$ were assigned to $\mathrm{C}-\mathrm{N}$ stretch 


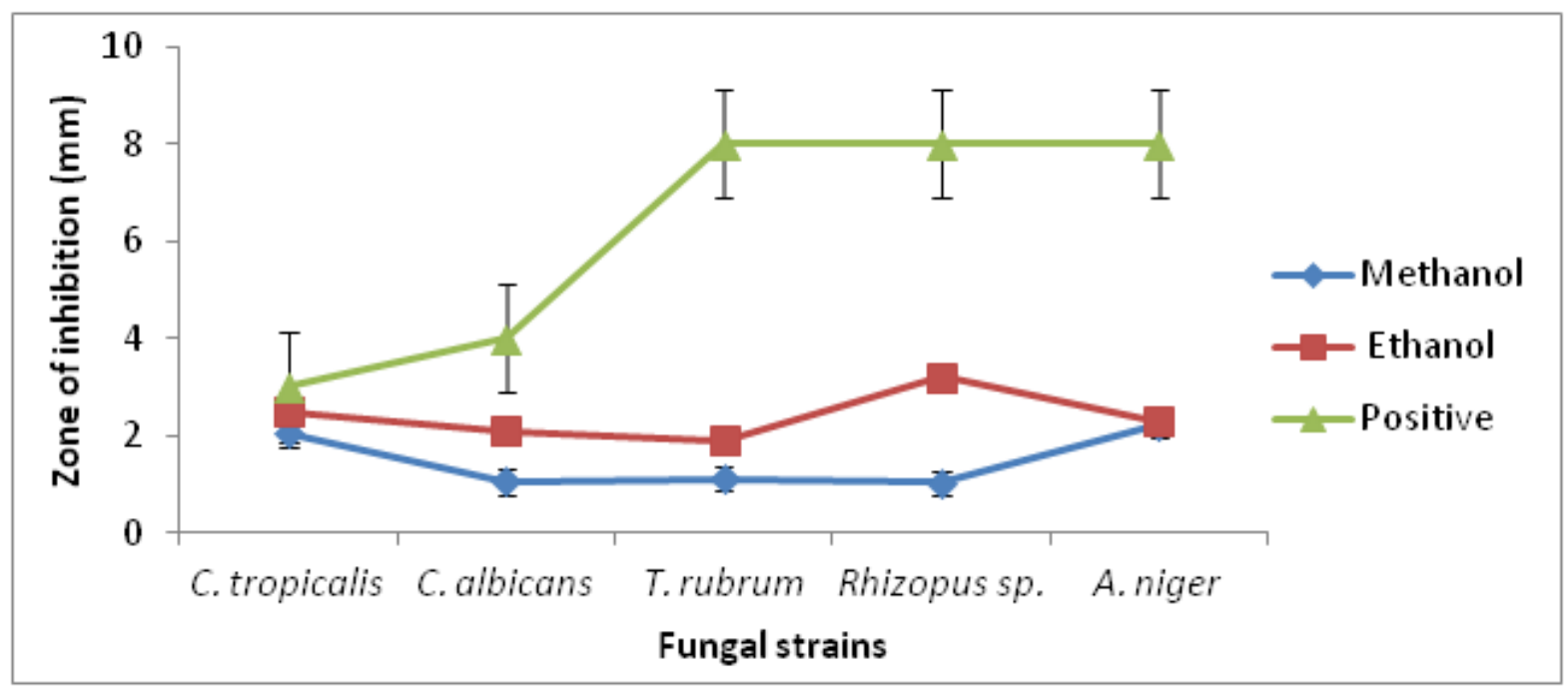

Figure 4. Antifungal activity of $O$. marmorata against human pathogens

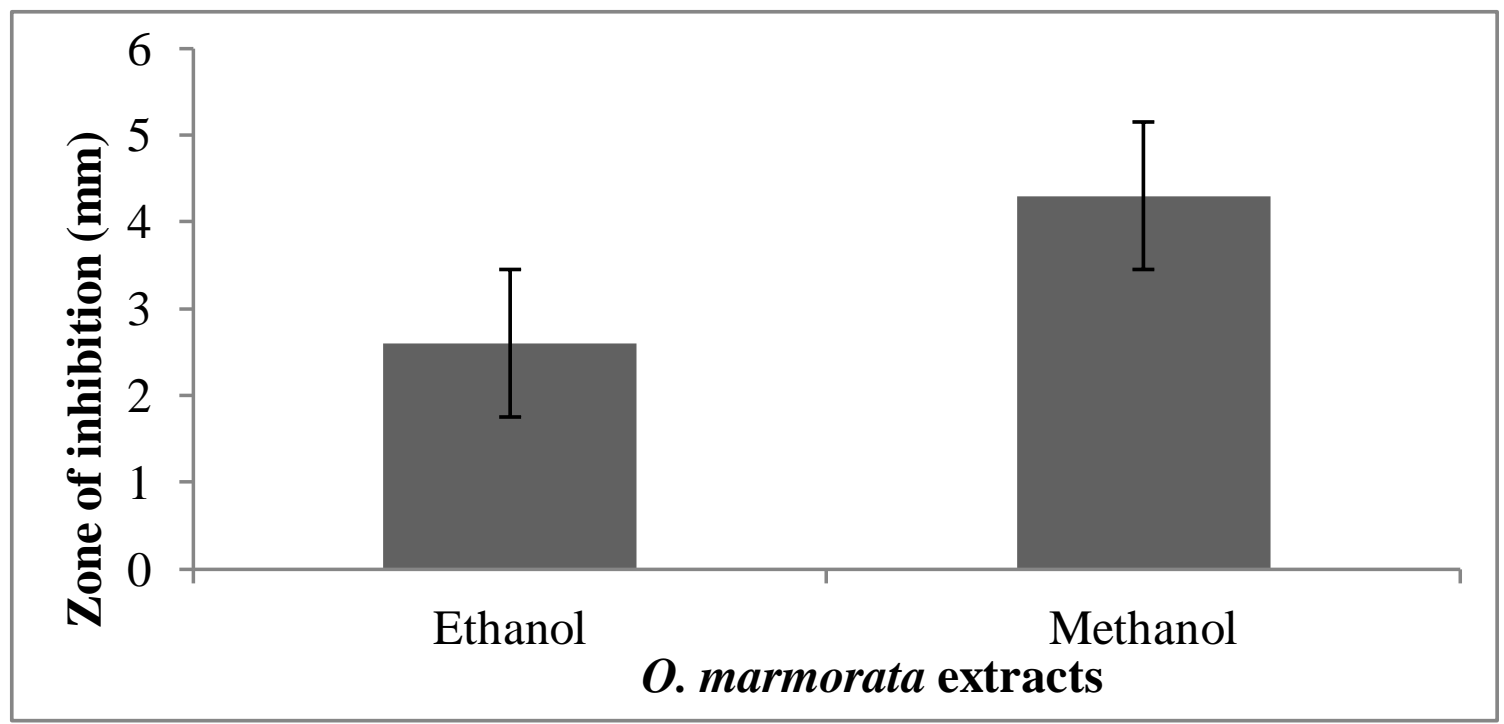

Figure 5. Hemolytic activity of chicken blood samples (Blood agar plates)thin layer chromatography.

(aliphatic amine groups).

The spectrum, 1084 to $1044 \mathrm{~cm}^{-1}$ was assigned to C-O strengthening in the $\mathrm{COH}$ groups. This spectrum showed that the aromatic $\mathrm{C}-\mathrm{H}$ stretches were to the left of 3000 $\mathrm{cm}^{-1}$ and the alkyl C-H stretches were to the right of 3000 $\mathrm{cm}^{-1}$.

\section{DISCUSSION}

Echinodermata is one of the most distinct phyla among the marine invertebrates, which include sea lilies, feather stars, brittle stars, sea stars, sand dollars, sea urchins, sea biscuits and sea cucumbers. Most of the appro- ximately 6,000 echinoderms are marine species with none of them living in freshwater (Pechenick, 2000). Organisms that belong to this phylum were proven to contain antibacterial, antifungal, antiviral, antitumor, anticoagulant, cytotoxic, hemolytic, antithrombotic and even anti-HIV agents. In this present investigation, crude extracts have been isolated from $O$. marmorata by using different solvent extracts like ethanol and methanol which are universal solvent that could extract even the basic proteins.

Rio et al. (1965) demonstrated some biochemical and physiological properties from Asteroidea sp., with water soluble fractions. Sunahara et al. (1987) extracted two toxins from the body extracts of Anthopleura fuscoviridis 


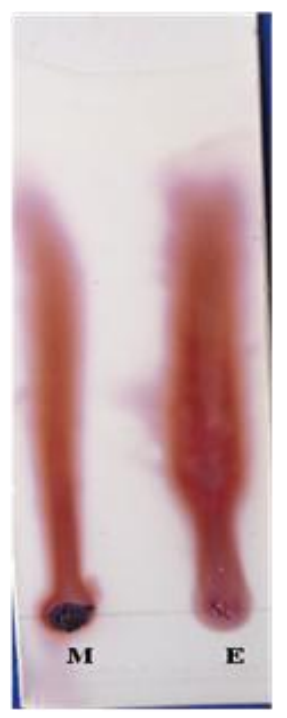

A

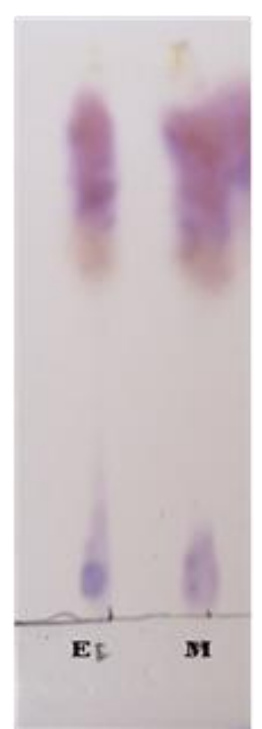

B

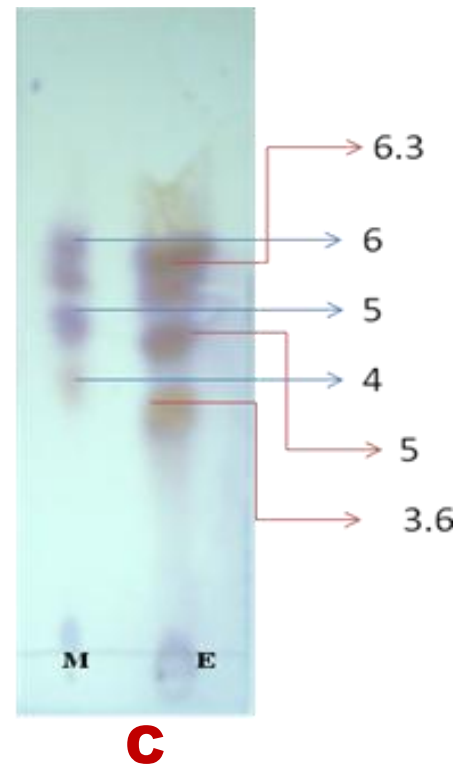

Figure 6. Thin layer chromatography of $O$. marmorata.

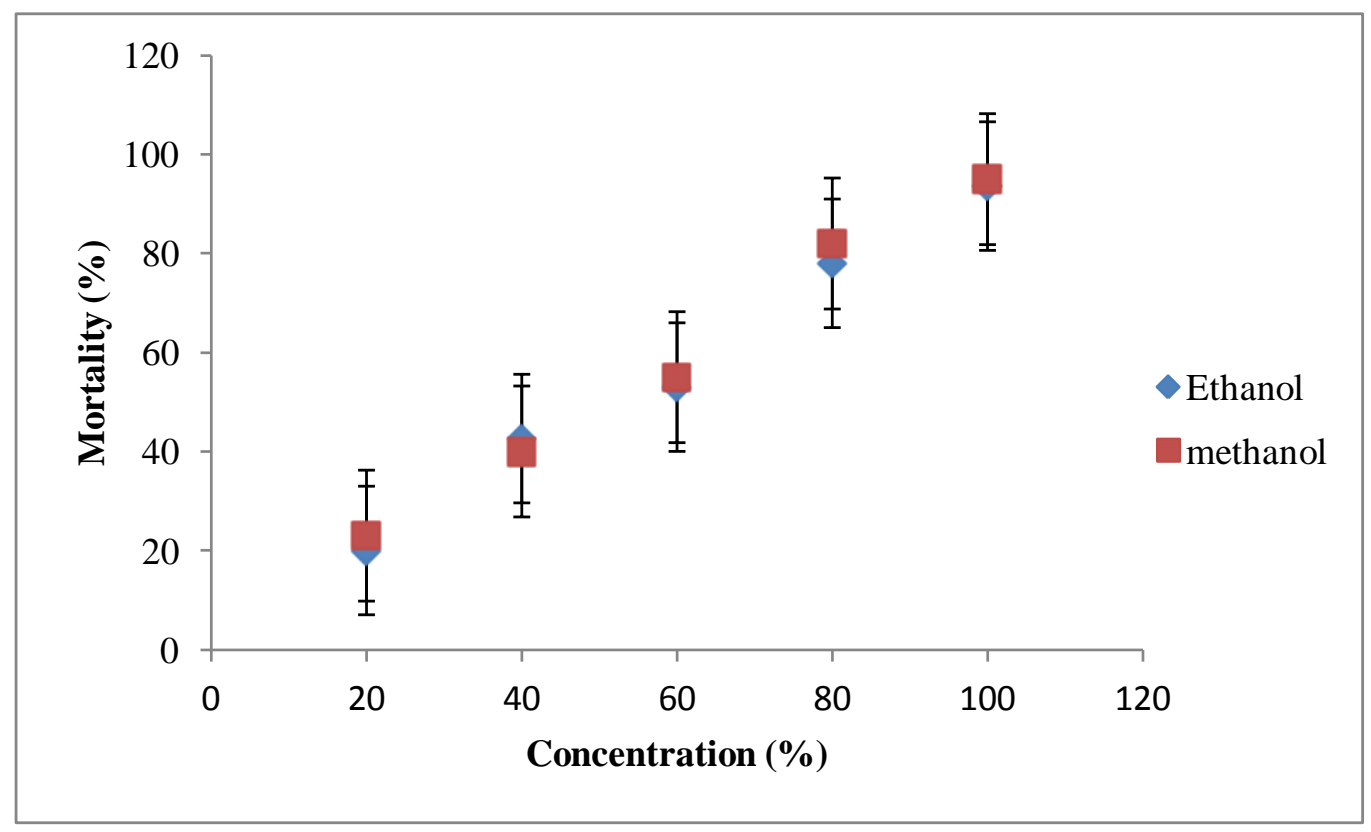

Figure 7. Cytotoxicity of $O$. marmorata extract against Artemia salina.

using methanol as extraction medium. Kanagarajan et al. (2008) reported that the protein content of the crude toxin/fractions was $531 \mu \mathrm{g} / \mathrm{mL}$ while the amount of protein in the purified fractions varied between $29 \mu \mathrm{g} / \mathrm{mL}$ (fractions F1, F5 and F7) and $68 \mu \mathrm{g} / \mathrm{mL}$ (fraction F4). The present investigation also coincides with previous study on the extraction of crude/fraction toxic proteins (4.14, 3.63 and $17.5 \%$ ) from the body of Protoreaster linckii. Karasudani et al. (1996) purified an anticoagulant factor from the spine venom of the crown-of-thorns starfish
Acanthaster planci. Antiadhesive mucintype glycoproteins were characterized from the mucus secretions of starfish Marthasterias glacialis and Porania pulvillus, and the brittle star Ophiocomina nigra (Bavington et al., 2004). Suguna (2011) recently reported the protein concentration of $4.14 \%$ in crude methanolic extract of starfish Protoreaster linckii.

Several drug discovery projects have screened for echinoderms for antibiotic activities. An early study by Rinehart et al. (1981) showed that antimicrobial activity 
ФSHIMADZU

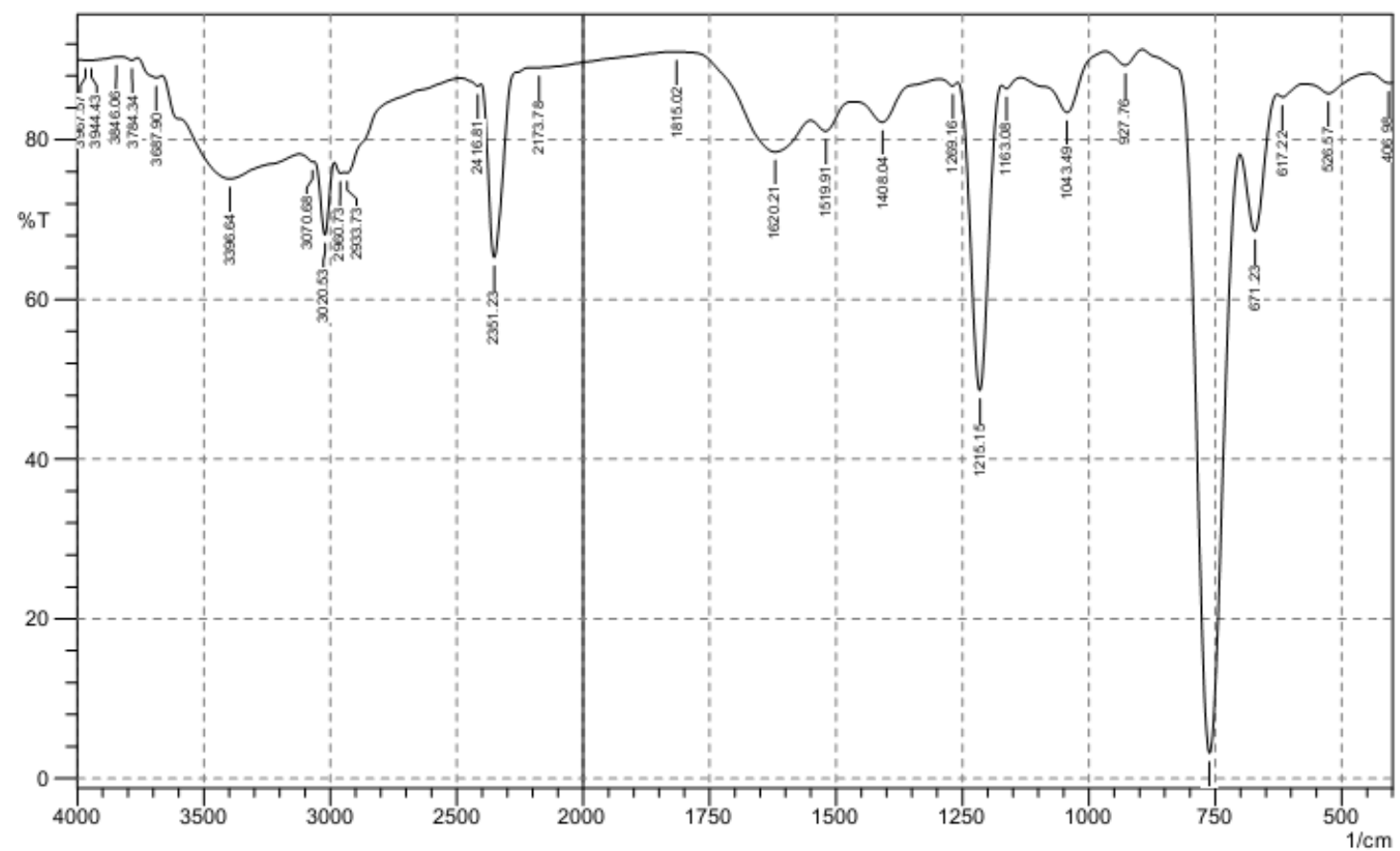

Figure 8. FTIR analysis of $O$. marmorata of methanolic extract.

\section{ФSHIMADZU}

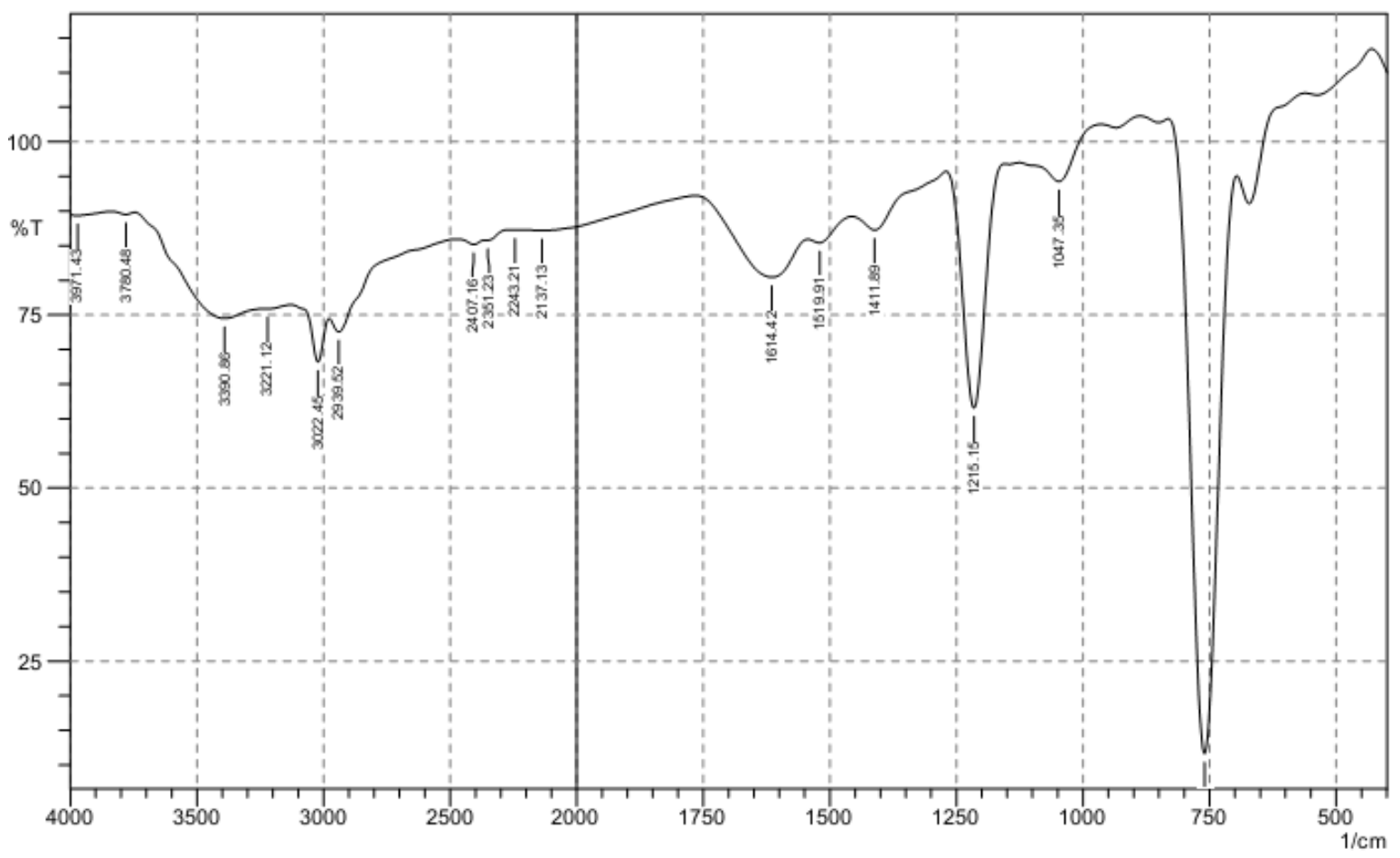

Figure 9. FTIR analysis of $O$. marmorata of ethanolic extract. 
was present in $43 \%$ of 83 unidentified species of echinoderms (collected from the West coast of Baja California and the Gulf of California) and $58 \%$ of 36 unidentified Caribbean species displayed antimicrobial activities. Ridzwan et al. (1995) isolated glycosides from holothurians and found they are inactive against gram (+) and gram (-) bacteria. On the other hand, starfishes and brittle stars were inactive against gram negative bacterium, E. coli and showed activities against gram positive, bacterium, $S$. aureus, including the polyhydroxylated steroid glycosides, polyhydroxylated sterol and disulfated sterol (Andersson et al., 1989).

Gerardi et al. (1990) found that the highest bacterial growth inhibition against several Vibrio sp. is shown by phagocytes and red spherule cells of Paracentrotus lividus. Stabili et al. (1996) also discovered antibacterial activity against $V$. alginolyticus in celomocytes lysates and coelomic fluid of $P$. lividus. Recently, Abraham et al. (2002) reported that the antibacterial and antifungal activities of the alcoholic extracts of holothurians were found to be inhibitory to human pathogens like $A$. hydrophilia, K. pneumonia, $P$. aeruginosa and $S$. aureus. The anti-microbial properties of echinoderm extracts mainly focus on their glycosides component, particularly the saponin (triterpene glycosides) and saponins-like components that are present on the polar fraction of echinoderm samples (Ivanchina et al., 2000; Avilov et al., 2000 and Maier et al., 2001).

Haug et al. (2002) have reported that antibacterial activity was detected in extracts of green sea urchin $S$. droebachiensis and sea star Asterias rubens. In the present investigation, brittle star $O$. marmorata also showed good activity against human pathogens (Figures 2 and 3). In the case of ethanol extract, the maximum zone of inhibition was recorded against $S$. aureus of 7.0 $\mathrm{mm}$ followed by $5.0 \mathrm{~mm}$ inhibition against $E$. coli and 4 $\mathrm{mm}$ of $V$. parahaemolyticus and $S$. typhi. One way ANOVA showed significance at $0.05 \%$ level $(p>0.05)$ between the extracts used whereas the methanol extracts exhibited maximum zone of inhibition against $K$. oxytoca $(9 \mathrm{~mm})$ followed by $K$. pneumonia and E. coli $(7$ $\mathrm{mm})$. One way ANOVA showed significance at $0.05 \%$ level $(p>0.05)$ between the extracts and positive control used.

Taira et al. (1975) firstly reported that the venom from Acanthaster planci involves lethal and hemolytic activities. The capacity of crude extract to lyse red blood cells was found by performing hemolytic assay on microtitre plates and blood agar plates. In this study, more hemolytic has occurred in goat blood. Rao et al. (1991) studied the bioactivity of marine organisms and found out that echinoderms are toxic to both fish and mice. They also exhibit strong hemolytic activity

Pereira et al. (1999) investigated the anticoagulant activity of echinoderm fucans in comparison with that of several species of brown algae and found that the linear sulfated fucans from echinoderms had an anticoagulant action resembling that of mammalian dermatan sulfate, whereas the branched fucans from brown algae were direct inhibitors of thrombin. Such differences have also been described for the linear sulfated fucans derived from sea cucumbers compared to algal fucans (Mulloy et al., 2000). Ito et al. (2002) studied the presence of paralytic shellfish poison (PSP) in the starfish Asterina pectinifera. The blood agar method has significant inhibitory effect on the cytolytic activity of the toxin. Recently, Kanagarajan et al. (2007) and Bragadeeswaran et al. (2011) reported the hemolytic activity of fish epidermal mucus and star fish Stellaster equestris.

Carballo et al. (2002) used two brine shrimp assays to identify potential cytotoxic substancesr useful for cancer therapy. They incubated whole body extracts from three echinoderms (Holothuria impatiens, Pseudoconus californica, and Pharia pyramidata) that showed a strong cytostatic (growth inhibition) and cytotoxic effect against two human cell lines, lung carcinoma A-549 and colon carcinoma HT-29. Palagiano et al. (1996) isolated up to 20 steroid glycosides from the starfish Henricia downeyae that causes growth inhibition in bacteria and fungi. In this work, it is remarkable that the biological activity originally identified in ethanolic extracts was related to single compounds whose molecular structures were even identified. Aminin et al. (1995) first identified in the Pacific brittle star Ophiopholis aculeate, disulfated polyhydroxysteroids that turned out to be potent $\mathrm{Ca}^{2+}$ agonists in mammalian cell systems (Aminin et al., 1995; Agafonova et al., 2002). In conclusion for the present study, methanol and ethanol extracts exhibited antimicrobial and hemolytic properties. Thin layer chromatography showed the band with different distance which indicates that the presence of active compounds may be responsible for the biological activities.

Our result entails the search for novel bioactive compounds by screening of different pathogenic microbes from efficient sourcing method. The results of the present study could present that marine invertebrates showed antimicrobial and cytotoxic properties against human bacterial pathogens and brine shrimp $A$. salaina. This preliminary investigation has revealed that many of these marine organisms produce more or less structurally diverse secondary metabolites which could be of Pharmaceutical interest.

\section{ACKNOWLEDGMENT}

The authors are grateful to the Dean, CAS in Marine Biology, Annamalai University for providing necessary facilities and encouragement and grateful to the University Grants Commission, Government of India for providing the research funding.

\section{REFERENCES}

Abraham TJ, Nagarajan J, Shanmugam SA (2002). Antimicrobial 
substance of potential biomedical importance from Holothurians species. Indian J. Mar.Sci. 31(2):161-164.

Abu GO, Weiner RM, Rice J, Colwell RR (1991). Properties of an extracellular adhesive polymer from the marine bacterium Shewanella colwelliana. Biofouling. 3:69-84.

Agafonova IG, Aminin DL, Shubina LK, Fedorov SN (2002). Influence of polyhydroxysteroids on [Ca (2+)] (i). Steroids 67:695-701.

Amini, AA, Curwen RW, Klein AK, Egglin TK, Pollak J, Lee F, Gore JC (1995). Physics based snakes, Kalman snakes, and snake grids for feature localization and tracking in medical images. p. 363-364.

Andersson L, Bohlin L, lorizzi M, Riccio R, Minale L, Moreno LW (1989). Biological activity of some saponins and saponin like compounds from starfish and brittle-stars. Toxicon. 27:179-188.

Asai N, Fusetani N, Matsunaga S, Sasaki J (2000). Sex pheromones of the hair crab Erimacrus isenbeckii. Part 1: Isolation and structures of novel ceramides. Tetrahedron 56:9895-9899.

Bauer AW, Kirby WMM, Sherris JC (1966) Antibiotic susceptibility testing by a standardized single disc method. [J] Am. J. Clin. Pathol. 45(4):493-496.

Braekman JC, Daloze D, Stoller C, Van Soest RWM (1992). Chemotaxonomy of Agelas (Porifera: Demospongiae). Biochem. Syst. Ecol. 20(5):417-431.

Carballo LJ, Hernandez-inda LZ, Perzer P, Gravalos MD (2002). A comparison between two brine shrimp assays to detect in vitro cytotoxicity in marine natural products. Bio. Med. Cent. 2:1-10.

Luigi M, Raffaele R, Franco Z (1995). Structural studies on chemical constituents of echinoderms. Studies in Nat. Prod. Chem. 15(C):43110.

Prokofeva NG (2003). Biological activities of steroid glycosides from starfish. Comp. Biochem. Physiol. Part B, 134:695-701.

Palagiano E, Zollo F, Minale L, lorizzi M, Bryan P, McClintock J, Hopkins T (1996). Isolation of 20 glycosides from the starfish Henrica downeaye, collected in the Gulf of Mexico. J. Nat. Prod. 59:348-354.

Prasad, KP, Venkateshvaran K (1997). Microhaemolytic Assay. In: International Training Manual on Advance Techniques in Marine Biotoxinology, Venkateshvaran, K. and K.P. Prasad (Eds.). Central Institute of Fisheries Education, India, pp.41.
Rinehart Jr KL, Shaw PD, Shield LS, Gloer JB, Harbour GC, Koker MES, Samain D, Schwartz RE, Tymiak AA, Weller DL, Carter GT, Munro M HG, Hughes Jr RG, Renis HE, Swynenberg EB, Stringfellow DA, Vavra JJ, Coats JH, Zurenko GE, Kuentzel SL, Li LH, Bakus GJ, Brusca RC, Craft LL, Young DN, Connor JL (1981). Marine natural products as sources of antiviral, antimicrobial and antineoplastic agents. Pure Appl. Chem. 53:795-817.

Sasaki T, Hasegawa-Sasaki H (1985). Breakdown of phosphatidylinositol 4, 5-bisphosphate in a T-cell leukaemia line stimulated by phytohaemagglutinin is not dependent on $\mathrm{Ca} 2+$ mobilization. Biochem. J. 227:971-979.

Schillacci G, Pucci G, De Socio GVL (2009). HIV infection and antiretroviral treatment: a "two-hit" model for arterial stiffness. Am. J. Hypertens. 22:817-818.

Seeman P, Cheng D, lles GF (1973). Structure of membrane holes in osmotic and saponin hemolysis. J. Cell Biol. 56:519-527.

Stabili L, Pagliara P, Roch P (1996). Antibacterial activity in the celomocytes of the sea urchin Paracentrotus lividus. Comp. Biochem. Physiol. 113B:639-644. 